\title{
Engagement in Everyday Activities among People Living in Indian Nursing Homes: The Association with Person-Centredness
}

\author{
Benedicte Sørensen Strøm ${ }^{a}$ Knut Engedal $^{b, c} \quad$ Anne Marie Rokstad ${ }^{\text {b, } d}$ \\ ${ }^{a}$ Faculty of Health Studies, VID Specialized University, Oslo, Norway; ${ }^{b}$ Norwegian Advisory \\ Unit for Aging and Health, Vestfold Hospital HF, Tønsberg, Norway; ${ }^{\mathrm{C}}$ Department of \\ Geriatrics, Oslo University Hospital, Tønsberg, Norway; ${ }^{d}$ Faculty of Health Science and \\ Social Care, Molde University College, Molde, Norway
}

Keywords

Everyday activities $\cdot$ Person-centred care $\cdot$ Nursing home $\cdot$ India

\begin{abstract}
Introduction: It has been reported that residents living in nursing homes are often inactive and lonely and are offered a limited number of activities. However, high engagement in activities has been reported to improve residents' quality of life and engagement in personalized activities can even reduce agitation and enhance positive mood. Information regarding occupational patterns and purpose in life is well established in Western countries. However, we know next to nothing about how people living in Indian nursing homes spend their days. Objective: To explore the participation in everyday activities among older people in Indian nursing homes and the extent to which engagement in activities is associated with personcentred care. Methods: The study was conducted in 6 nursing homes in India, comprising 147 residents. In all, 23 nursing staff took part and completed a 26 -item questionnaire about resident activities based on the Multi-Dimensional Dementia Assessment Scale and the PersonDirected Care Questionnaire. Person-centredness was measured with the Person-Centred Care Assessment Tool. Results: We found low participation in everyday activities among the residents. Participation in religious activities was the most frequent, whereas the least used activities were excursions, participating in cultural activities, taking part in educational programmes, visiting a restaurant and going to the cinema. A significant positive association was found between person-centred care and participation in religious activities, engagement in an activity programme and physical activity. Conclusions: The most frequently attended activity was religious activities. Person-centred care was associated with participation in religious activities, engagement in an activity programme, physical activity, spending time in the garden and playing and listening to music.




\section{Introduction}

By 2050, India's population aged 60 years and older is expected to encompass 323 million people. Many of them will be in need of care, and thus, India's system of family-based support will not be able to withstand the increased number of older Indians with functional impairments [1] since traditional family-based care is becoming less common [2,3]. This trend is due to lower birth rates, migration for employment, more women taking up employment and children moving out $[4,5]$. The increased life expectancy among old people in India will lead to more need for geriatric care and support [6], and this change requires a shift in resources and services to respond to an aging population [7].

It has been reported that residents living in nursing homes are often inactive and lonely [8] and are offered a limited number of activities [9]. This limitation exists despite the recommendation from NICE [10] to provide activities for older people living in nursing homes. High engagement in activities has been reported to improve residents' quality of life [11], and engagement in personalized activities can even reduce agitation [12] and enhance positive mood [13]. It has also been reported that being engaged in various hobbies [14] and housekeeping activities [15] could enhance residents' quality of life. Furthermore, engagement in everyday activities can support personhood and thriving among nursing home residents [16]. Nevertheless, Palacios-Cena et al. [17] questioned whether the importance of providing meaningful activities in nursing homes was understood by the staff. This sentiment was supported in Kada et al. [18] who revealed that nursing staff doubted that the residents derived any benefit or joy in attending activities. This attitude is not consistent with the philosophy of person-centred care. The cornerstone of person-centred includes empowering nursing home residents to take independent choices in life and participate in decision making with regard to provision of care and activities [19-21]. Person-centredness is an approach to practice, established through a healthful relationship between care providers, care recipients and significant others in the care recipients' lives. It is underpinned by values of respect for persons, individual right to self-determination, mutual respect and understanding. It is enabled by cultures of empowerment that foster continuous approaches to practice development [22]. In recent decades, person-centred dementia care has been introduced as the worldwide intervention of choice to develop high-quality dementia care in nursing homes $[19,21,23]$. Essential elements of person-centred dementia care have been described in the VIPS framework as valuing people with dementia (V), individualized care (I), understanding the world from the perspective of the person with dementia (P) and providing a social environment that supports the needs of the person (S) [24]. However, the implementation of person-centred practice in nursing homes have been described as a complex and challenging intervention [25]. Organizational factors such as the size of the unit [25, 26], staff levels [27] and leadership [28-30] appear to influence the outcome of the interventions.

Information regarding occupational patterns and purpose in life is well established in Western countries. However, we know next to nothing about how people living in Indian nursing homes spend their days. Hence, the aim of this study is to explore the participation in everyday activities among older people in Indian nursing homes and the extent to which engagement in everyday activities is associated with person-centred care. Even though the sample size is relatively small, this study to our knowledge is the first study of its kind in India.

\section{Material and Methods}

A cross-sectional design was used to collect data on participation in activities and personcentredness in Indian nursing homes. 


\section{Sampling and Participants}

This study was conducted in 6 nursing homes in India, all run by religious orders, of which 4 are located in Tamil Nadu, 1 in Goa and 1 in Maharashtra. Two of the nursing homes are located in rural areas, providing care for poor people, whereas the other nursing homes are located in cities. One provides care for people from the middle class and 3 for members of the religious orders.

The nursing homes were all used as clinical placements for Norwegian nursing students in project management. All the 147 residents and 23 English-speaking nursing staff in the nursing homes were eligible for the study.

\section{Data Collection}

One student in each nursing home was appointed to oversee the study and serve as the contact person between this article's first author and the director of nursing. The residents' data were collected in January and February 2018 and January and February 2019 over a 5-day period. A period of 5 days was chosen in order to be able to compare it with a similar study conducted in Sweden [16]. The assessments were made by 17 Norwegian Bachelor of Nursing students in their third academic year. In order to ensure that their data collection method was uniform, this article's first author provided a training in the use of the assessment tools.

The data related to the residents' age and gender were obtained from the residents' records. The nursing staff participants were asked for information related to their age, level of education and years of experience working in geriatric care.

\section{Instruments}

To evaluate the residents' engagement in everyday activities and activity type engaged in over a period of 5 days, a 26-item questionnaire described by Bjork et al. [16] was used. The 26 items are based on the Multi-Dimensional Dementia Assessment Scale [31] and the Person-Directed Care Questionnaire by White et al. [32]. The engagement items were formulated as statements; for example, "Estimate if the residents were engaged in the following activities the last 5 days." Furthermore, a dichotomous scale with yes or no options was also included. The Multi-Dimensional Dementia Assessment Scale has demonstrated satisfactory intra- and interreliability [31].

All care staff were invited to provide self-reported data on person-centred care using the Person-Centred Care Assessment Tool (P-CAT). The P-CAT was developed as a self-report assessment scale for care staff to rate the extent to which their care practice was considered person-centred [33]. The P-CAT questionnaire consists of 13 items formulated as statements about person-centredness, and a 5-point scale ranging from 1 (disagree completely) to 5 (agree completely) is used for scoring purposes, giving a possible range of 13-65 [33]. Based on factor analyses, two subscales have emerged to evaluate the extent of personalized care, with a possible score range of 8-40, and the extent of organizational and environmental support, with a possible score range of 5-25 [34]. The scale has been reported as having satisfactory psychometric properties [33, 34].

\section{Statistical Analyses}

Descriptive statistics was used to describe the residents' age and gender and their engagement in everyday activities. In addition, staff age, years of experience working with older people and education were described. The categorical data were presented as percentages, whereas continuous data were presented as means and standard deviations. The 26 everyday activities were coded into 7 activity categories, partly based on the Occupational Therapy Practice Framework: Domain and Process 3rd edition [35], and presented as percentages. 
Strøm et al.: Everyday Activities in Nursing Homes

Table 1. Characteristics of the older people and nursing staff

\begin{tabular}{|c|c|c|c|c|c|c|c|}
\hline & \multirow[t]{2}{*}{ Total } & \multicolumn{6}{|c|}{ Nursing homes } \\
\hline & & A & B & $\mathrm{C}$ & $\mathrm{D}$ & $\mathrm{E}$ & $\mathrm{F}$ \\
\hline Residents, $n$ & 147 & 20 & 25 & 20 & 39 & 30 & 13 \\
\hline \multicolumn{8}{|l|}{ Gender, $n$} \\
\hline Women & 137 & 20 & 23 & 12 & 39 & 30 & 13 \\
\hline Male & 10 & 0 & 2 & 8 & 0 & 0 & 0 \\
\hline Residents' mean age, years & 76.8 & 84.8 & 79.8 & 72.8 & 76 & 71.6 & 79.3 \\
\hline Participating nursing staff, $n$ & 23 & 7 & 4 & 4 & 5 & 1 & 2 \\
\hline Nurses & 14 & 4 & 4 & 2 & 2 & 1 & 1 \\
\hline Non-nurses & 9 & 3 & 0 & 2 & 3 & 0 & 1 \\
\hline Nursing staff mean age, years & 53.4 & 43.8 & 57 & 63.7 & 50.4 & 72 & 57.5 \\
\hline $\begin{array}{l}\text { Nursing staff mean years of } \\
\text { experience in older people care }\end{array}$ & 8.9 & 2.8 & 25 & 5.2 & 4.4 & 28 & 6.5 \\
\hline Over 5 years, $n$ & 11 & 1 & 3 & 3 & 2 & 1 & 1 \\
\hline Below 5 years, $n$ & 12 & 6 & 1 & 1 & 3 & 0 & 1 \\
\hline
\end{tabular}

Before analysing the P-CAT data, the responses on negative statements in the questionnaire were recorded and reversed. The mean value of the total score of person-centeredness and the two subscales were calculated for each nursing home. The association between engagement in activities and level of person-centred care was explored using independent $t$ tests, where the significant level was set at a $p$ value of $<0.01$. The analyses were performed using the Statistical Package for Social Sciences (SPSS) version 26. There was no missing data.

\section{Results}

As shown in Table 1, the mean age of the 147 residents was $76.8 \pm 10.2$ years, ranging from 40 to 94 years, and 137 (86.7\%) were women. The one person below 65 years of age was placed in the nursing home due to multiple handicaps. The mean age of the 23 nursing staff was $53.4 \pm 17.1$ years, and all of them were women. Their mean years of working experience in geriatric care was $8.9 \pm 11.3$ years, and $11(47.8 \%)$ had over 5 years of experience. Most of the nursing staff $(60.9 \%)$ were registered nurses, whereas 9 (39.1\%) were nursing assistants or without formal education in health care.

\section{Observed Participation in Everyday Activities}

As described in Table 2, the mean participation in the 26 everyday activities was $9.7 \pm$ 3.7 , ranging from $13.5 \pm 3$. to $6.2 \pm 2.1$. Among social and relational activities, participating in religious activities was the most commonly used activity, as 127 (86.4\%) of the residents took part. Other common occurring everyday activities the residents participated in during the week included the following: dressing nicely (81.6\%), spending time with someone they like $(72.8 \%)$ and talking to relatives and friends (68\%). A total of $89(60.5 \%)$ of the residents received hugs and physical touch regularly and 83 (56.5\%) were doing everyday chores. The least used activities observed were being on excursions (2.7\%), participating in cultural activities $(2.7 \%)$, taking part in an educational programme (1.4\%), visiting a restaurant $(0.7 \%)$ and going to the cinema $(0 \%)$.

In 2 of the nursing homes ( $\mathrm{A}$ and $\mathrm{C}$ ), nearly all residents were engaged in physical activities regularly ( 85 and 100\%, respectively); however, in the other 4 nursing homes, fewer 




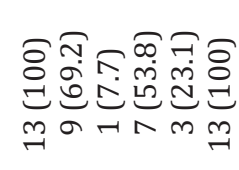

กี่

소곳

สกลอกา

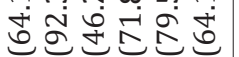



듬응ㅎㅀ

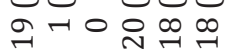

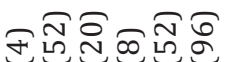

$\rightarrow M$ L $N$ N

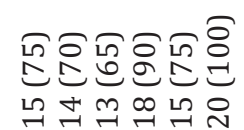

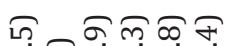

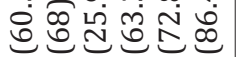

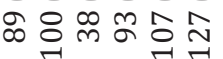

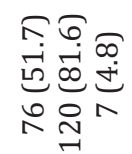

๙ $\stackrel{\infty}{\infty} \infty$

을월

원ㄱ

ㅇㅠㄹㅀ 吉

을율웡

$m \circ$

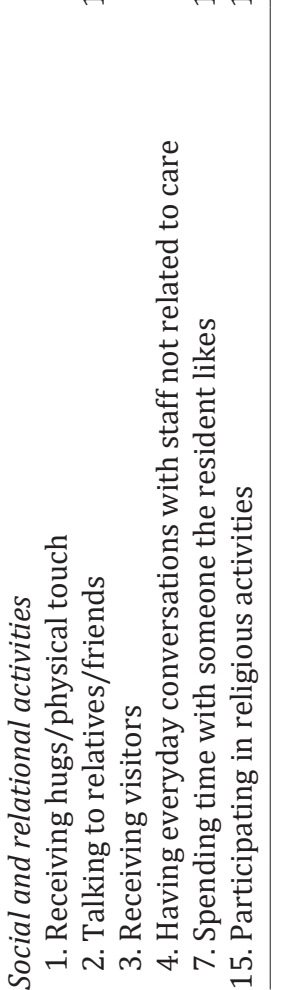

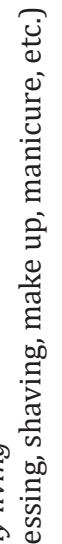
สี 产


: 20 휴 궝 पे 20. $\stackrel{\Xi}{\Xi} .00 \pi$


பी

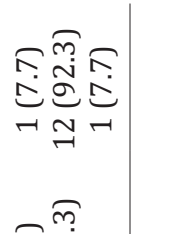

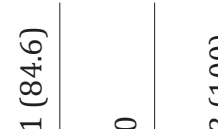
$\underbrace{0}_{\substack{0 \\ 0}} 00$ 尺ิ है $\exists 0000$ - 76

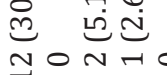

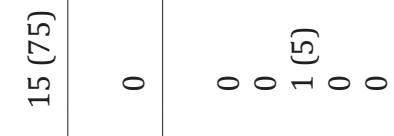
Ð $\rightarrow 0000$

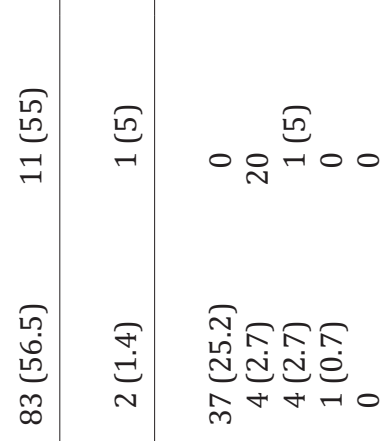
ते

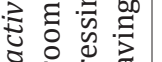







residents took part, ranging from 3.3 to $28 \%$. Engaging regularly in an activity programme was reported in 2 nursing homes, A and F ( 90 and 61.5\%, respectively), whereas only few of the residents in the other 4 nursing homes were engaged in this kind of activity.

In 3 of the nursing homes (A, B and C), the residents were often playing and listening to music, whereas this was rarely observed in the other 3 nursing homes. Receiving hugs and physical touch was observed in most nursing homes, except in 1 (B), where this was reported to be observed in only $4 \%$ of the residents. In most nursing homes, except for 1 (B), the residents performed everyday chores. None of the residents visited cinemas, and only 1 resident in nursing home D was observed to visit a restaurant.

\section{Person-Centred Care as Measured using P-CAT}

The P-CAT scores in the participating nursing homes are presented in Table 3 . The mean P-CAT score was $49.3 \pm 6.6$. Nursing home B reported the highest score $(55.7 \pm 1.2)$, and nursing home D the lowest $(39.6 \pm 6.5)$. Furthermore, the mean score for "extent of personalized care" was $29.6 \pm 4.2$, whereas the mean "organizational and environmental support" score was $19.5 \pm 3.1$. Nursing home B also scored the highest on both subscores, and nursing home D had the lowest scores on both subscales.

\section{The Association between Person-Centred Care and Participation in Everyday Activities}

The association between P-CAT scores and participation in everyday activities is illustrated in Table 4. No significant correlations between the mean number of activities the residents engaged in and evaluation of person-centred care as measured by P-CAT ( $p=0.394)$ were found. However, residents who participated in group activities, such as an activity programme ( $p=0.037)$ and physical activities $(p=0.001)$, lived in nursing homes with significantly higher P-CAT scores as compared to those who did not. Furthermore, a significant association was found between higher P-CAT scores and certain leisure activities such as playing and listening to music $(p=0.000)$ and being outside the nursing home $(p=0.010)$. Participating in religious activities was also positively associated with higher P-CAT scores $(p=0.000)$. Residents being engaged in everyday chores lived in nursing homes with a significantly lower P-CAT score ( $p=0.013)$, a trend which was also reported for most of the social and relational activities, such as talking to friends ( $p=0.000)$, receiving visitors $(p=0.002)$, having everyday conversation with staff not related to care $(p=0.001)$ and spending time with someone the residents like $(p=0.002)$ (Table 4$)$.

\section{Discussion}

The aim of this study was to explore the participation in everyday activities among older people in Indian nursing homes and the extent to which engagement in everyday activities was associated with person-centred care.

In general, we discovered low participation in everyday activities. Participation in religious activities was the most frequent activity. Additionally, we discovered that residents who engaged in religious activities, activity programmes, physical activities and who spent time in the garden, played and listened to music lived in nursing homes that reported more person-centred care practice. Furthermore, more than half of the residents participated in householding activities. Few residents were engaged in physical activities. Participation in education programmes, watching cinema and visiting restaurants were the least commonly engaged activities.

The relatively low participation among the residents in everyday activities was consistent with previous findings of Edvardsson et al. [36] and Kjøs and Havig [9]. The low participation 
Table 4. The association between everyday activities and level of person-centred care (mean score)

\begin{tabular}{|c|c|c|c|}
\hline & $\begin{array}{l}\text { P-CAT } \\
\text { yes }\end{array}$ & $\begin{array}{l}\text { P-CAT } \\
\text { no }\end{array}$ & $p$ value \\
\hline \multicolumn{4}{|l|}{ Play activities (group) } \\
\hline 12. Engaging in an activity programme & 50.6 & 48 & 0.037 \\
\hline 13. Engaging in physical activity & 50.8 & 47.3 & 0.001 \\
\hline 22. Playing parlour games with others & 49.7 & 48.2 & 0.262 \\
\hline \multicolumn{4}{|l|}{ Leisure activities (individual) } \\
\hline 6. Watching TV & 49.7 & 47.7 & 0.055 \\
\hline 9. Playing or listening to music & 50.1 & 46.6 & 0.000 \\
\hline 10. Being outside the nursing home (in the garden) & 49.5 & 47 & 0.010 \\
\hline 11. Reading book and newspapers & 47.7 & 49.9 & 0.194 \\
\hline 17. Interacting with pets & 48.3 & 48.5 & 0.909 \\
\hline 19. Engaging in a hobby & 45.9 & 49.2 & 0.007 \\
\hline 21. Writing or drawing & 46 & 49 & 0.015 \\
\hline \multicolumn{4}{|l|}{ Social and relational activities } \\
\hline 1. Receiving hugs/physical touch & 47.8 & 49.4 & 0.111 \\
\hline 2. Talking to relatives/friends & 46.9 & 51.7 & 0.000 \\
\hline 3. Receiving visitors & 45.8 & 49.3 & 0.002 \\
\hline 4. Having everyday conversations with staff not related to care & 47.2 & 50.5 & 0.001 \\
\hline 7. Spending time with someone the resident likes & 47.5 & 50.9 & 0.002 \\
\hline 15. Participating in religious activities & 49.3 & 42.8 & 0.000 \\
\hline \multicolumn{4}{|l|}{ Basic activities for daily living } \\
\hline 5. Grooming (hairdressing, shaving, make up, manicure, etc.) & 48 & 49 & 0.316 \\
\hline 8. Dressing nicely & 48.8 & 46.8 & 0.110 \\
\hline 20. Having a massage & 51 & 48.3 & 0.256 \\
\hline \multicolumn{4}{|l|}{ Instrumental activities for daily living } \\
\hline 23. Doing everyday chores (making coffee, setting the table, etc.) & 47.7 & 49.9 & 0.013 \\
\hline \multicolumn{4}{|l|}{ Educational activities } \\
\hline 25. Taking part in an educational programme & 44.6 & 48.5 & 0.367 \\
\hline \multicolumn{4}{|l|}{ Outings and cultural activities } \\
\hline 14. Participating in celebrations & 48.1 & 48.6 & 0.663 \\
\hline 16. Participating in cultural activities & 49.7 & 48.4 & 0.688 \\
\hline 18. Being on excursions & 45.1 & 48.6 & 0.256 \\
\hline 24. Visiting a restaurant & 39.6 & 48.5 & 0.140 \\
\hline 26. Going to the cinema & $\mathrm{N} / \mathrm{A}$ & N/A & N/A \\
\hline
\end{tabular}

rate is of concern since lack of stimulation can lead to apathy, boredom, loneliness and even loss of functional skills [37]. The importance of providing everyday activities is also emphasized by the potential of meaningful activities to improve the residents' quality of life $[14,36$, 38], enhance positive mood [39] and even increase the experience of dignity [40]. The current study did not focus on the reason for the lack of activities; therefore, the reasons for this deficiency remain unknown. However, Kada et al. [18] demonstrated that providing activities was not considered part of traditional nursing care for older people. This might explain our findings since the mean age of the nursing staff was relatively high (54.4 years).

Another explanation could be that staff do not think that residents benefit from activities [18]. Nevertheless, this is not consistent with the fact that the majority of the nursing staff said that residents were offered the opportunity to be involved in individualized everyday activities as reported in one of the items in the P-CAT questionnaire. A possible explanation 
could be in line with the findings of Mondaca et al. [41], who suggested that the deeper meaning of everyday activities might remain invisible to the staff representing and focusing on the institutional routines, or as Smebye and Kirkevold [42] indicated in their study: the activities were not self-evident in the context of nursing homes.

Workload or the high prevalence of residents with cognitive impairment in nursing homes have also been suggested as possible explanations for the lack of provision of activities [43]. It is therefore interesting to observe that the majority of the 23 nursing staff in our study reported that they did not have time to provide person-centred care, and this finding might explain the relatively low participation rate in everyday activities.

The high participating rate in religious activities is not consistent with results of previous studies in Sweden [16]. Only few residents participated in religious activities. Similar findings were reported by Edvardsson et al. [36] and Tak et al. [44], where a minority of the residents had been taken to church during the 1-week observation period. The frequent participation in religious activities reported in our study could probably be explained by the fact that all 6 nursing care homes were run by religious orders and, therefore, had daily mass and prayer. The importance of offering the residents religious activities was supported in Edvardsson et al. [36], who revealed that those who participated in church visits lived in significantly more person-centred nursing homes and had higher quality of life. The significant positive association between person-centred care and participation in religious activities was also demonstrated in our study.

It was interesting to observe that more than half of the residents in the study participated in householding activities at least once a week, which is a much higher percentage than in Edvardsson et al. [36], den Ouden et al. [45] and Bjork et al. [16], as these studies reported that very few participated in householding activities. The promising findings in our study of residents being engaged in everyday chores are supported by the research of Cooney et al. [38]. This kind of engagement has been reported to positively influence residents' quality of life [36] and even to support their sense of self [46]. It might therefore be of concern that nursing home residents in the Western world are offered more organized activities instead of being offered the opportunity to continue engaging in more natural, daily activities. The higher attendance in daily chores found in our study might be explained by the fact that older people who live in nursing homes in India most probably have a higher functional capacity to take care of their activities of daily living (ADL) than residents in European nursing homes. These hypothetical considerations are based on personal and non-documented experiences made by the first author and need to be explored further in future research. Another factor which might explain our findings could be the workload and lack of time to organize activities, as well as a lack of understanding of the importance of keeping older persons occupied with self-directed activities as long as possible. However, it was interesting to observe that residents who were engaged in everyday chores resided in less person-centred nursing homes. This might be explained by the fact that the nursing staff simply allowed the residents to engage in whatever activities they could cope with as long as possible.

The number of residents engaged in physical activities was relatively low considering the recommendations by the World Health Organization (WHO) that older people above 65 years of age should at least have $30 \mathrm{~min}$ of regular physical activity of moderate intensity on most days [47]. In addition, research has emphasized that older people should remain physically active as this can decrease the risk of many age-related conditions [48]. The low participation in physical activities in our study was in line with previous studies from Sweden where only approximately half of the residents had been engaged in physical activities during the week [16]. Nevertheless, the Study on Global Ageing and Adult Health (SAGE) Wave 1, which was implemented in India in 2007 as part of a multi-country study in 6 countries to overcome this gap, revealed that older Indians were reasonably active [49]. In comparison, approximately 
half of older people living in Indian slums were found to be physically active, which was positively associated with better quality of life [50]. However, in a study conducted by Kalavar et al. [51] investigating the activity patterns among nursing home residents in India, one third of the residents were not engaged in physical activities at all. Furthermore, it is interesting to observe that residents in our study who were engaged in physical activities lived in nursing homes where person-centred care was practiced.

The low participation in education programmes, watching cinema and visiting restaurants might be explained by Indian culture and available resources or by the fact that the majority of residents either were religious sisters or came from a poor background, which meant that they were not used to having hobbies or going to restaurants and cinemas. However, the findings were consistent with a study by Bjork et al. [16] in Sweden that also found that few residents went to the cinema or visited restaurants. In addition, Edvardsson et al. [36] emphasized that residents in nursing homes were at risk of having limited possibilities to engage in self-selected activities and to keep in touch with the community outside the nursing home. Tomioka et al. [52], therefore, suggested that engagement in hobbies and encouraging purpose in life may be useful in preventing decline in basic ADL and instrumental ADL, such as allowing the person to perform daily courses and reducing the risk of mortality. Studies have even suggested that such activities may delay cognitive deterioration [53]. The importance of allowing residents to engage in hobbies was supported in the study by Tak et al. [44], in which nursing home residents expressed that they missed past hobbies greatly.

Only 2 of the nursing homes reported having an activity programme. Even though relatively few residents participated in an activity programme, this result reflected the findings of previous research. One study suggested that engagement in activity programmes had the strongest positive association with residents thriving in nursing home [16]. Residents in the present study who participated in an activity programme lived in nursing homes with significantly higher P-CAT scores. The same association was found among those who played and listened to music and spent time outside the nursing home. Providing an activity programme for residents living in a nursing home is a relatively new concept in the Western world as well. It is therefore interesting that residents expressed that a fixed activity schedule prevented them from being able to make their own choices regarding participation in activities [44]. The possibility of having a choice of activities as well as activities that matter to them was experienced as meaningful and might therefore be as important as providing a scheduled activity programme. Additionally, there appeared to be a change in staff attitude to the traditional activity calendar, and as an alternative, residents were empowered to choose and lead their own ongoing and spontaneous activities and chores [54].

\section{The Importance of Activities to Enhance Person-Centred Care}

According to the person-centred care philosophy, to be occupied and engaged in personally significant activities is a basic psychological need [55]. The alternative is a state of boredom, apathy and futility. No single activity can meet the needs of all residents; some have the need for individualized activities, whereas others have a need to provide desirable activities. Therefore, the more the staff know about the persons' past and particularly their deepest source of satisfaction, the more likely it is that they are able to offer tailored and meaningful activities to them [55]. It is not only a question of keeping the residents busy but also one of allowing them to attend activities that are relevant and meaningful to their lives.

It is interesting to observe that most of the activities described in the Indian nursing homes were individual social and relational activities, and few of them were organized group activities. Only 2 of the nursing homes had organized group activities. A review by Strøm et al. [56] revealed that group-based music sessions appeared to have a better effect than indi- 
vidual sessions. These findings illustrate the positive potential of organizing group activities for nursing home residents. However, to organize group activities in nursing homes, some basic framework conditions need to be present; namely, the staff's understanding of the importance of such activities and available resources to organize them. As the staff responding to the P-CAT questionnaire mainly disagreed that they had enough time to offer personcentred care (Table 3), time appeared to be a constrained resource. The need for a culture change from a task-oriented approach to a person-centred approach has been emphasized for several years [55,57]. The importance of staff understanding and attitudes in developing a culture of person-centred care is obvious, as is the need for organizational support and engaged leaders [28-30]. Culture change requires a sense of shared purpose and empowers the staff to take responsibility for the residents' well-being [58]. Numerous staff training programmes to enhance person-centred care have been conducted. Factors that contribute to an effective training programme in care were investigated in a recent review by Surr et al. [59] identifying the common features of the most effective programmes: the importance of an experienced facilitator, providing training directly relevant to the participant's roles, building on previous experience and involving active face-to-face participation. Therefore, replacing the nursing staff with activity coordinators is not recommended. Instead, everyday activities should be used as an opportunity to develop a person-centred relationship between nursing staff and residents.

One limitation of this study was the relatively few participants. Furthermore, all the nursing homes were run by religious orders. Nevertheless, the study provides an important contribution in terms of shedding light on the conditions in Indian nursing homes.

Another limitation was that the activity scale used in this study was relatively old (from 1988) and not adjusted to the Indian context. However, nursing homes in India are a new concept and to our knowledge, no similar studies have been conducted in India.

\section{Conclusion}

The findings of the current study are relevant as being engaged in activities has been reported as improving residents' quality of life. The residents most frequently attended religious activities; however, the low engagement in physical activities remains a source of concern. Person-centred care was associated with participation in religious activities, engagement in an activity programme, physical activity, spending time in the garden and playing and listening to music.

\section{Acknowledgement}

We would like to express our gratitude to the nursing students from VID Specialized University in Oslo, Norway, for their contributions to this study in collecting data.

\section{Statements of Ethics}

The study was approved by the Norwegian social science data services (NSD). As no residents were interviewed or examined, ethical approval was not required according to the Norwegian Act of medical and health research, as confirmed by the NSD (ref. no. 57526).

However, ethical approval was obtained from the board of management in each nursing home. The need of obtaining approval from the Health Ministry's Screening Committee of 
India was considered; however, we were informed that only biomedical and health research conducted after September 2019 need ethical approval.

The sampling was based on voluntary participation. Informed consent was obtained from the residents, or from the next of kin if the person did not have the capacity to complete the consent form. The nursing staff who were willing to participate in the study signed the consent form.

\section{Disclosure Statement}

The authors have no conflicts of interest to declare.

\section{Funding Sources}

The authors have not received any funding for this study.

\section{Author Contributions}

Benedicte Strøm, Knut Engedal and Anne Marie Rokstad contributed to the design of the research and analysis of the data, while Benedicte Strøm collected the data.

\section{References}

1 Bloom DE. Population Dynamics of India and Implications for Economic Growth. Harvard Program on the Global Demography of Aging Working Paper 65 (January 2011). 2012. Available from: www.hsph.harvard. edu/pgda/working/.htm.

2 Armstrong R, Kergoat H. Oculo-visual changes and clinical considerations affecting older patients with dementia. Ophthalmic Physiol Opt. 2015 Jul;35(4):352-76.

3 Arokiasamy P, Bloom D, Lee J, Feeney MP, Ozolins M. Longitudinal Aging Study in India (LASI): vision, desing, implementation, and some early results. PGDA Working Paper No 82. 2010. Available from: http://citeseerx. ist.psu.edu/viewdoc/download?doi=10.1.1.697.7373\&rep=rep1\&type=pdf.

4 Deshingkar P, Akter S. Migration and human development in India. Human Development Reports. United Nations Development Programme. 2009. Available from: http://hdr.undp.org/en/content/migrationand-human-development-india.

5 Krishnaswamy B, Sein UT, Munodawafa D, Varghese C, Venkataraman K, Anand L. Ageing in India. Ageing Int. 2008;32(4):258-68.

6 Ugargol AP, Hutter I, James KS, Bailey A. Care Needs and Caregivers: Associations and Effects of Living Arrangements on Caregiving to Older Adults in India. Ageing Int. 2016;41(2):193-213.

7 Chatterji S, Kowal P, Mathers C, Naidoo N, Verdes E, Smith JP, et al. The health of aging populations in China and India. Health Aff (Millwood). 2008 Jul-Aug;27(4):1052-63.

8 Harper Ice G. Daily life in a nursing home: has it changed in 25 years? J Aging Stud. 2002;16(4):345-59.

9 Kjøs BØ, Havig AK. An examination of quality of care in Norwegian nursing homes - a change to more activities? Scand J Caring Sci. 2016 Jun;30(2):330-9.

10 NICE. Dementia. London: NICE; 2019.

11 Bergman-Evans B. Beyond the basics. Effects of the Eden Alternative model on quality of life issues. J Gerontol Nurs. 2004 Jun;30(6):27-34.

12 Kolanowski AM, Litaker M, Buettner L. Efficacy of theory-based activities for behavioral symptoms of dementia. Nurs Res. 2005 Jul-Aug;54(4):219-28.

13 Van Haitsma KS, Curyto K, Abbott KM, Towsley GL, Spector A, Kleban M. A randomized controlled trial for an individualized positive psychosocial intervention for the affective and behavioral symptoms of dementia in nursing home residents. J Gerontol B Psychol Sci Soc Sci. 2015 Jan;70(1):35-45.

14 Drageset J, Natvig GK, Eide GE, Bondevik M, Nortvedt MW, Nygaard HA. Health-related quality of life among old residents of nursing homes in Norway. Int J Nurs Pract. 2009;15(5):455-66.

15 Funaki Y, Kaneko F, Okamura H. Study on factors associated with changes in quality of life of demented elderly persons in group homes. Scand J Occup Ther. 2005 Mar;12(1):4-9. 
Björk S, Lindkvist M, Wimo A, Juthberg C, Bergland Å, Edvardsson D. Residents' engagement in everyday activities and its association with thriving in nursing homes. J Adv Nurs. 2017 Aug;73(8):1884-95.

17 Palacios-Ceña D, Gómez-Calero C, Cachón-Pérez JM, Velarde-García JF, Martínez-Piedrola R, Pérez-De-Heredia M. Is the experience of meaningful activities understood in nursing homes? A qualitative study. Geriatr Nurs. 2016 Mar-Apr;37(2):110-5.

18 Kada S, Nygaard HA, Mukesh BN, Geitung JT. Staff attitudes towards institutionalised dementia residents. J Clin Nurs. 2009 Aug;18(16):2383-92.

19 Edvardsson D, Winblad B, Sandman PO. Person-centred care of people with severe Alzheimer's disease: current status and ways forward. Lancet Neurol. 2008 Apr;7(4):362-7.

20 McCormack B, McCance T. Person-centred nursing: theory and practice. Chichester (West Sussex): WileyBlackwell; 2010. https://doi.org/10.1002/9781444390506.

21 Kitwood T. Dementia reconsidered: the person comes first. Buckingham: Open University Press; 1997.

22 McCormack B, McCance T. Person-Centred Practice in Nursing and Health Care. Oxford: John Wiley \& Sons Ltd; 2017.

23 Fazio S, Pace D, Flinner J, Kallmyer B. The Fundamentals of Person-Centered Care for Individuals With Dementia. Gerontologist. 2018;58(suppl_1):S10-S19.

24 Brooker D, Lathan I. Person-Centred Dementia Care. London: Jessica Kingsley Publishers; 2016.

25 Rosvik J, Engedal K, Kirkevold O. Factors to make the VIPS practice model more effective in the treatment of neuropsychiatric symptoms in nursing home residents with dementia. Dement Geriatr Cogn Disord. 2014; 37(5-6):335-46.

26 Zuidema SU, de Jonghe JF, Verhey FR, Koopmans RT. Environmental correlates of neuropsychiatric symptoms in nursing home patients with dementia. Int J Geriatr Psychiatry. 2010 Jan;25(1):14-22.

27 Collier E, Harrington C. Staffing characteristics, turnover rates, and quality of resident care in nursing facilities. Res Gerontol Nurs. 2008 Jul;1(3):157-70.

28 Damschroder LJ, Aron DC, Keith RE, Kirsh SR, Alexander JA, Lowery JC. Fostering implementation of health services research findings into practice: a consolidated framework for advancing implementation science. Implement Sci. 2009 Aug; 4(1):50.

29 Jeon YH, Merlyn T, Chenoweth L. Leadership and management in the aged care sector: a narrative synthesis. Australas J Ageing. 2010 Jun;29(2):54-60.

30 Rokstad AM, Vatne S, Engedal K, Selbæk G. The role of leadership in the implementation of person-centred care using Dementia Care Mapping: a study in three nursing homes. J Nurs Manag. 2015 Jan;23(1):15-26.

31 Sandman PO, Adolfsson R, Norberg A, Nyström L, Winblad B. Long-term care of the elderly. A descriptive study of 3600 institutionalized patients in the county of Västerbotten, Sweden. Compr Gerontol A. 1988 Oct;2(3): 120-32.

32 White DL, Newton-Curtis L, Lyons KS. Development and initial testing of a measure of person-directed care. Gerontologist. 2008 Jul;48(Spec No 1 suppl 1):114-23.

33 Edvardsson D, Fetherstonhaugh D, Nay R, Gibson S. Development and initial testing of the Person-centered Care Assessment Tool (P-CAT). Int Psychogeriatr. 2010 Feb;22(1):101-8.

34 Rokstad AM, Engedal K, Edvardsson D, Selbaek G. Psychometric evaluation of the Norwegian version of the Person-centred Care Assessment Tool. Int J Nurs Pract. 2012 Feb;18(1):99-105.

35 American Occupational Therapy Association. Occupational Thearapy Practice Framework: Domain \& Process. 3rd ed. AOTA Press; 2014.

36 Edvardsson D, Petersson L, Sjogren K, Lindkvist M, Sandman PO. Everyday activities for people with dementia in residential aged care: associations with person-centredness and quality of life. Int J Older People Nurs. 2014 Dec;9(4):269-76.

37 Cacioppo JT, Hughes ME, Waite LJ, Hawkley LC, Thisted RA. Loneliness as a specific risk factor for depressive symptoms: cross-sectional and longitudinal analyses. Psychol Aging. 2006 Mar;21(1):140-51.

38 Cooney A, Murphy K, O'Shea E. Resident perspectives of the determinants of quality of life in residential care in Ireland. J Adv Nurs. 2009 May;65(5):1029-38.

39 Beerens HC, Zwakhalen SM, Verbeek H, E S Tan F, Jolani S, Downs M, et al. The relation between mood, activity, and interaction in long-term dementia care. Aging Ment Health. 2018 Jan;22(1):26-32.

40 Slettebø ̊̊, Saeteren B, Caspari S, Lohne V, Rehnsfeldt AW, Heggestad AK, et al. The significance of meaningful and enjoyable activities for nursing home resident's experiences of dignity. Scand J Caring Sci. 2017 Dec;31(4): 718-26.

41 Mondaca M, Josephsson S, Katz A, Rosenberg L. Influencing everyday activities in a nursing home setting: A call for ethical and responsive engagement. Nurs Inq. 2018 Apr;25(2):e12217.

42 Smebye KL, Kirkevold M. The influence of relationships on personhood in dementia care: a qualitative, hermeneutic study. BMC Nurs. 2013 Dec;12(1):29.

43 Cohen-Mansfield J, Bester A. Flexibility as a management principle in dementia care: the Adards example. Gerontologist. 2006 Aug;46(4):540-4.

44 Tak SH, Kedia S, Tongumpun TM, Hong SH. Activity Engagement: Perspectives from Nursing Home Residents with Dementia. Educ Gerontol. 2015 Mar;41(3):182-92.

45 den Ouden M, Bleijlevens MH, Meijers JM, Zwakhalen SM, Braun SM, Tan FE, et al. Daily (In)Activities of Nursing Home Residents in Their Wards: An Observation Study. J Am Med Dir Assoc. 2015 Nov;16(11):963-8. 
Davis S, Byers S, Nay R, Koch S. Guiding design of dementia friendly environments in residential care settings: considering the living experiences. Dementia. 2009;8(2):185-203.

47 WHO. Global recommendations on physical activity for health. Geneva: WHO; 2010.

48 Shaheen M, Puri S, Tandon N. Physical Activity Measurement in Elderly: The Indian Scenario. J Phys Act Res. 2016;1(1):9-14.

49 Arokiasamy P, Parasuraman S, Sekher TV, Lhungdim H. Study on global AGEing and adult health (SAGE) Wave 1: India National Report. International Institute for Population Sciences. Geneva: WHO; 2013.

50 De S, Roy RN, Mitra K, Das DK, Dan A. Physical activity is positively associated with quality of life of slum dwelling elderly. IOSR J Dent Med Sci. 2018;17(5):67-73.

51 Kalavar JM, Jamuna D, Ejaz FK. Elder abuse in India: extrapolating from the experiences of seniors in India's "pay and stay" homes. J Elder Abuse Negl. 2013;25(1):3-18.

52 Tomioka K, Kurumatani N, Hosoi H. Relationship of Having Hobbies and a Purpose in Life With Mortality, Activities of Daily Living, and Instrumental Activities of Daily Living Among Community-Dwelling Elderly Adults. J Epidemiol. 2016 Jul;26(7):361-70.

53 Cheng ST, Chow PK, Song YQ, Yu EC, Lam JH. Can leisure activities slow dementia progression in nursing home residents? A cluster-randomized controlled trial. Int Psychogeriatr. 2014;26(4):637-43.

54 Doty MM, Koren MJ, Sturla EJ. Culture Change in Nursing Homes: How Far Have We Come? Findings From The Commonwealth Fund 2007 National Survey of Nursing Homes. The Commonwealth Fund. 2008. Available from: https://www.commonwealthfund.org/publications/fund-reports/2008/may/culture-change-nursinghomes-how-far-have-we-come-findings.

55 Kitwood T, Brooker D. Dementia Reconsidered, Revised. The Person Still Comes First. London: Open University Press; 2019.

56 Strøm BS, Ytrehus S, Grov EK. Sensory stimulation for persons with dementia: a review of the literature. J Clin Nurs. 2016 Jul;25(13-14):1805-34.

57 McCormack B, McCane T. Person-Centred Practice in Nursing and Health Care: Theory and Practice. New Jersey: Wiley-Blackwell; 2016.

58 Killett A, Burns D, Kelly F, Brooker D, Bowes A, La Fontaine J, et al. Digging deep: how organisational culture affects care home residents' experiences. Ageing Soc. 2016;36(1):160-88.

59 Surr CA, Gates C, Irving D, Oyebode J, Smith SJ, Parveen S, et al. Effective Dementia Education and Training for the Health and Social Care Workforce: A Systematic Review of the Literature. Rev Educ Res. 2017 Oct;87(5): 966-1002. 